\title{
International perspective on mixed health care: United Kingdom
}

\author{
Andrew Vallance-Owen
}

When the National Health Service (NHS) was founded in 1948, the consultants-medical and surgical specialists-could only be persuaded to come on board by giving them contracts which allowed them to pursue private practice outside the time they devoted to their NHS work. Nye Bevan, the health minister at the time, was accused of "stuffing their mouths with gold," and many felt the NHS practice would be given lower priority, but the compromise worked and most consultants who have undertaken private practice over the years have also regularly worked more than their contracted hours for the NHS.

The NHS enabled all the people of the country to receive health care for free at the point of need, as it still does to a large extent (prescription charges for drugs being one exception), but some have always wanted additional access to private health care and have been prepared to 'top up' by buying private medical insurance or by paying for private health care directly. Most straightforward private medicine is undertaken in small independent hospitals, but more complex treatment may be undertaken in NHS hospitals, with patients being accommodated in private or pay bed wards.

In many ways the NHS has been very successful; for people who suffer trauma or acute illness the service is excellent, and the primary care system has been second -to-none. However, those with chronic conditions and those needing routine elective surgery have had a less good service which, for the latter, has often meant long waits. Many have argued that health care in the UK has

\footnotetext{
*To whom correspondence should be addressed: Andrew Vallance-Owen BUPA House 15-19 Bloomsbury Way London WC1A 2BA UK vallanca@bupa.com
}

been rationed by waiting; for example, not so long ago many patients could have waited over a year for total hip replacement. Indeed, up to quite recently, the principal reason given for buying private medical insurance (PMI) was to avoid waiting but, despite this issue, PMI uptake in the UK has been running at a fairly stable $12-13 \%$ for the last 10 years-partly because it is expensive.

In July 2000, the Labour Government adopted a new strategy for the NHS, the NHS Plan.* Reduction of waiting times became a key priority and, for the first time since the formation of the NHS, ministers decided that the NHS could contract with independent hospitals to use their spare capacity and reduce waiting lists. This was also a tactic, akin to throwing a grenade in a pool, to stir up NHS hospitals and persuade them to be more efficient because, at the same time, a new funding system for hospitals was introduced-payment by results-that brought in competition for patients, each bringing his funding with him.

This short article cannot fully cover the detail of these changes or the nature of the sticks and carrots used but, essentially, waiting times are now dropping significantly and consultants continue to maintain their private practice, although some are worried that the drop in waiting times will threaten the take up of PMI. There are, however, two other factors which might counter that concern.

First, given the problems that many NHS hospitals have been having with methicillin-resistant Staphylococcus aureus (MRSA) and Clostridium difficile, the top reason for purchase of PMI is now clean hospitals; independent hospitals have a much better record in this regard. Second, there have been increasing restrictions on what is available under the NHS. Cosmetic surgery, for instance, has been excluded for some time, and the National Institute for Clinical Excellence (NICE), which assesses the cost effectiveness of new drugs and technologies and acts as 
a gatekeeper for their use in the NHS, is regularly accused of rationing access to certain treatments.

Now, in the last year, private medical insurers and others have been invited to become involved in the demand as opposed to the supply side of the NHS. A separate part of the NHS Plan proposed the devolution of funding decisions from the centre and regions to primary care trusts (PCTs); these would be made more clearly responsible for assessing the needs of their local populations and purchasing (or 'commissioning') appropriate care from local hospitals and community services. The objective of these measures is to wrest power away from the large, expensive hospitals and bring more care, particularly for chronic disease, into the community.

The problem, however, has been that many PCTs have not had the experience to manage the change or the competence to drive this more strategic agenda. Thus, private insurers, who have to be competent in purchasing or commissioning care for private patients, have been asked to tender for contracts to support PCTs in undertaking this and other types of activity.

In summary, therefore, the independent sector in the UK has moved from being almost solely a parallel system to the NHS, with the only point of contact being consultants working in both systems, to a system from which the NHS is increasingly seeking support. Interestingly it is a Labour Government, traditionally opposed to private medicine, which has led this change. Their hope is that the NHS will improve so much that, as a result, the private sector in the UK will shrink and die. Whether this will happen remains to be seen.

* The NHS Plan: a plan for investment, a plan for reform Department of Health, Cm 4818-I July 2000

Andrew Vallance-Owen, MBChB, MBA, FSCSEd, is a graduate of the Birmingham University Medical School and undertook surgical training in Newcastle-upon-Tyne and Melbourne, Australia. He became Medical Director of British United Provident Association (BUPA) Hospitals in 1994 and, in 1995, became BUPA's Group Medical Director. He has expertise in health screening and promotion and is a keen advocate of improved doctor/patient communication and shared decision-making. He has considerable knowledge and experience in the field of health and medical politics. 